\title{
Learning to exchange an endotracheal tube for a laryngeal mask prior to emergence
}

\author{
[Apprendre à remplacer un tube endotrachéal par un masque laryngé avant le \\ retour à la conscience]
}

Michael S. Stix MD PhD, Carl J. Borromeo MD, Guy J. Sciortino MD, Paul D. Teague MD

Purpose: To present a stepwise training method, first critiquing laryngeal mask (LM) insertion difficulty and malpositioning, then learning how to exchange an endotracheal tube (ETT) for a LM during emergence from anesthesia.

Methods: "Learning phase:" sixty adults were enrolled in a preliminary study in which ETT / LM exchange was not performed - only LM insertion difficulty and malpositioning in the presence of an oral ETT were evaluated. After induction of anesthesia and oral intubation, a classic LM size 4 was inserted using the standard recommended technique. Number of insertion attempts and fibreoptically determined malpositions were recorded. "ETT / LM exchange phase:" we performed airway exchange in 50 patients selected from our individual practices.

Results: "Learning phase:" the LM was satisfactorily positioned, on first attempt, in $95 \%$ of cases. With multiple insertion attempts it was possible to place the LM in all 60 intubated patients. Unsuccessful initial placement of the LM was always due to insufficient insertion depth (5\%). When fully inserted into the hypopharynx, the epiglottis could be viewed fibreoptically in 13\% of cases. "ETT / LM exchange phase:" the LM was inserted successfully in all 50 patients on first attempt. No complications occurred during any exchange.

Conclusion: We found it is easy to learn how to insert a $L M$ in the presence of an oral ETT. The most serious malposition, occurring in $5 \%$ of first attempts, was insufficient insertion depth. The only other malposition we encountered, fibreoptic visualization of the epiglottis, is not likely to result in complete airway obstruction following endotracheal extubation under anesthesia. tissage de l'échange d'un tube endotrachéal (TET) pour un ML pendant le retour à la conscience après l'anesthésie.

Méthode : "Phase d'apprentissage" : 60 adultes ont été recrutés pour une étude préliminaire au cours de laquelle l'échange TET / $M L$ n'a pas été réalisé, mais où seulement la difficulté d'insertion et la malposition du ML, en présence d'un TET oral, ont été évaluées. Après l'induction de l'anesthésie et l'intubation orale, un ML typique de taille 4 a été inséré selon la technique standard recommandée. Le nombre d'essais nécessaires à l'insertion et de malpositions déterminées par fibroscopie a été noté. "Phase d'échange TET / ML" : l'échange a été réalisé chez 50 patients choisis parmi notre clientèle.

Résultats : "Phase d'apprentissage" : le ML a été mis en place de façon satisfaisante dans $95 \%$ des cas. Après de multiples essais, il a été possible d'insérer le ML chez les 60 patients intubés. Une malposition initiale du ML était toujours causée par une insertion insuffisamment profonde $(5 \%)$. Lorsque le ML était complètement inséré dans l'hypopharynx, on pouvait voir l'épiglotte par fibroscopie dans $13 \%$ des cas. "Phase d'échange TET / ML" : le Ml a été inséré avec succès chez les 50 patients au premier essai et aucune complication n'est survenue.

Conclusion : Nous avons constaté qu'il est facile d'apprendre à insérer un ML en présence d'un TET oral. La malposition la plus sérieuse, survenue dans $5 \%$ des cas au premier essai, a été une insertion insuffisamment profonde. La seule autre malposition notée, la visualisation fibroscopique de l'épiglotte, ne risque pas de provoquer d'obstruction complète des voies aériennes à la suite de l'extubation endotrachéale sous anesthésie.

Objectif : Présenter une méthode d'apprentissage progressif, comprenant d'abord la formulation de critiques sur les difficultés d'insertion et la malposition du masque laryngé (ML), puis l'appren-

From the Department of Anesthesiology, Lahey Clinic, Burlington, Massachusetts, USA

Address correspondence to: Dr. Michael S. Stix, Department of Anesthesiology, Lahey Clinic, 41 Mall Road, Burlington MA 01805 , USA. Phone: 781-744-8132 (Anesthesiology Department); 781-744-3140 (voice mail); Fax: 781-744-2273; E-mail

michael.s.stix@lahey.org istrative, forms).

Accepted for publication March 29, 2001.

Revision accepted May 14, 2001

CAN J ANESTH 2001 / 48: 8 / pp 795-799 
$\mathrm{O}$

NE of the advanced uses of the laryngeal mask (LM) is airway exchange. ${ }^{1}$ This refers to exchange of an endotracheal tube (ETT) for a LM prior to emergence from anesthesia. ${ }^{2-13}$ A smooth emergence without coughing and bucking is one of the anesthetic goals during neurosurgical, interventional neuroradiology, otolaryngological, ophthalmological, and many other surgical procedures. The incidence of coughing during emergence can be high; in one study involving isoflurane endotracheal anesthesia, more than $75 \%$ of patients coughed ten or more times prior to endotracheal extubation. ${ }^{14}$ By switching from an ETT to a LM, Koga et al. demonstrated a dramatic reduction in the incidence of coughing and bucking at the time of anesthetic emergence. ${ }^{11}$

There is a natural hesitancy to perform ETT / LM exchange. First, the procedure involves jeopardizing a secure airway. Second, for surgeries where exchange is most valuable, the patients often have significant co- $^{-}$ existing disease. Third, the procedure may be unfamiliar to surgeons and operating room staff. Fourth, instruction and supervision may be unavailable. For these reasons we utilized a stepwise method to learn this valuable manoeuver.

The anesthetic management of ETT / LM exchange involves deep anesthesia, sufficient for the patient to tolerate smooth LM insertion and endotracheal extubation. ${ }^{2-13}$ Because the LM occupies the hypopharynx, behind the larynx, it can be placed while the patient remains intubated orally. ${ }^{1,6-13}$ The exchange manoeuver involves placing the LM behind the oral ETT, followed by endotracheal extubation under deep anesthesia. Placing the LM prior to ETT extubation allows the practitioner to act unhurriedly and helps avert problems should multiple LM insertion attempts be needed. ${ }^{6-13}$

We first performed a study of 60 patients in which we assessed LM positioning in orally intubated patients. We recorded the number of LM insertion attempts and also fibreoptically evaluated the quality of LM positioning / malpositioning in the presence of an existing oral ETT. ETT / LM exchange was not performed in these 60 patients - only LM insertion difficulty and malpositioning were evaluated. After gaining experience with these LM insertions in intubated patients and with an understanding of the incidence and causes of LM malpositions we began incorporating ETT / LM exchange into our clinical practice. We summarize our first $\mathbf{5 0}$ cases of actual ETT / LM exchange.

\section{Methods}

I. "Learning phase" of study

Hospital Institutional Review Board approval and patient informed consent was obtained. Sixty adult patients (40 men, 20 women), aged $24-84 \mathrm{yr}$, were enrolled. After induction of anesthesia and oral intubation, a classic LM size 4 was inserted using the standard recommended technique ${ }^{15}$ and the cuff inflated with $20 \mathrm{~mL}$ air. The number of insertion attempts was recorded; an attempt was considered unsuccessful if it took greater than $20 \mathrm{sec}$ or the LM was removed from the patient's mouth. ${ }^{16}$ Using fibreoptic (FOB) examination via the airway tube of the LM, the presence of malposition was then evaluated:1,17,18

Insufficient insertion depth:

FOB view of lingual tissue; FOB view tip of LM proximal to arytenoids; FOB view esophageal inlet.

Excessive insertion depth:

No FOB view of glottis; FOB view of esophageal mucosa.

LMA folded: $\quad$ FOB view of LM cuff folded backwards.

LMA twisted: $\quad$ FOB view LM rotated with respect to glottis.

Epiglottis viewed: $\quad$ FOB view of tip of epiglottis; epiglottis to right or left of the ETT; epiglottis folded back on self by ETT.

ETT / LM exchange was not carried out in this phase of our study. In these 60 patients the LM was simply removed after insertion attempts and positioning were recorded.

\section{II. "ETT / LM exchange phase" of study}

In the second stage of our study a total of 50 patients were selected from our individual clinical practices for ETT / LM exchange. All ETT / LM exchanges included deep inhalational anesthesia, with or without muscle relaxation and positive pressure ventilation (at the discretion of the anesthesiologist). Prior to exchange an orogastric tube was passed and the stomach suctioned. The pharynx was suctioned using a Yankauer tip. Anesthetic depth was judged sufficient if the patient failed to respond to suctioning and if the jaw felt relaxed. The anesthetic was deepened at this point if the patient responded to these stimuli. With the ETT taped to the right hand side of the mouth, the LM was then inserted using the standard recommended technique ${ }^{15}$ and the cuff inflated. Usually size 5 LMs were used for males and size 4 for females. The LM was secured, along with a bite block, using tape 


\begin{tabular}{ll} 
TABLE Summary of 50 ETT / LM exchanges \\
\hline No. & Surgery \\
\hline 3 & Craniotomy - aneurysm \\
4 & Craniotomy - tumour \\
1 & Craniotomy - seizure focus \\
1 & Skull base - glomus jugulare \\
1 & Skull base - facial nerve graft \\
2 & Interventional neuroradiology \\
4 & Carotid endarterectomy \\
2 & Thyroidectomy \\
3 & Neck mass and dissection \\
4 & Anterior cervical fusion \\
1 & Cervical laminectomy \\
1 & Thoracotomy and lobectomy \\
1 & Median sternotomy \\
5 & Peripheral arterial revascularization \\
2 & Lumbar laminectomy \\
2 & Laparascopic surgery \\
6 & Hysterectomy / GYN \\
2 & Breast surgery \\
1 & Prostatectomy \\
1 & Cystectomy and ileal loop \\
3 & Orthopedics - extremeties \\
\hline
\end{tabular}

on the left cheek and across the nose. Shortly thereafter the trachea was extubated.

\section{Results}

I. "Learning phase" of study

In the first part of our study we found that it was possible to place the LM in all 60 orally intubated patients. First time insertion success occurred in $57 / 60(95 \%)$ of cases. In 3/60 (5\%) cases more than one attempt was necessary to fully insert the LM.

In those cases where more than one insertion attempt was required, LM malposition was always "insufficient insertion depth." The typical FOB view obtained, with the LM fully inserted, is illustrated with two examples in Figure 1; the tip of the LM lies behind the cricoid cartilage, both arytenoids are viewed, and the ETT (appearing with moisture) is seen traversing the glottis. The next most common fibreoptic view, with the LM fully inserted, is illustrated in Figure 2. Here the epiglottis is visualized. The epiglottis was viewed in 8/60 (13\%) of cases (full insertion depth). No other malpositions were visualized.

\section{II. "ETT / LM exchange phase" of study}

The Table summarizes our first 50 actual ETT / LM exchanges. The range of cases illustrates the value of this important airway manoeuver. The LM was inserted successfully on the first attempt in all 50 cases. Immediately following endotracheal extubation under deep anesthesia it was never necessary to remove the

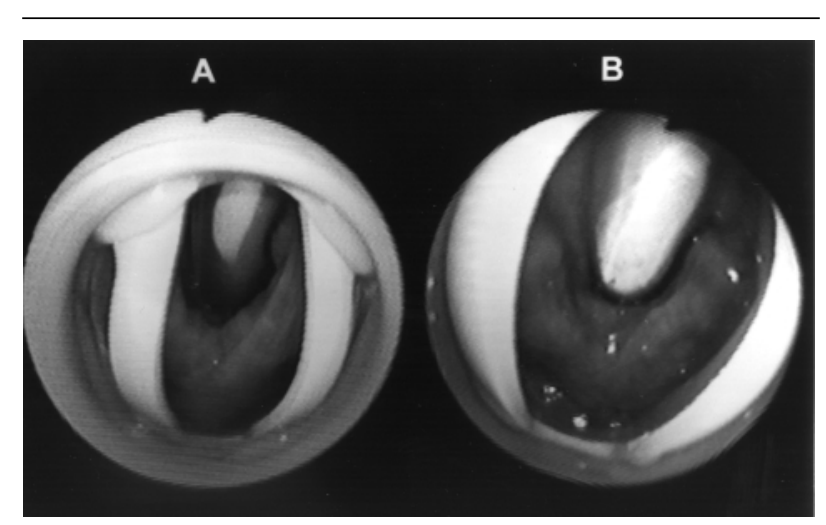

FIGURE 1 Typical fibreoptic views with the laryngeal mask (LM) fully inserted. A and B are different patients. The endotracheal tubes appear moisture-laden in both examples.

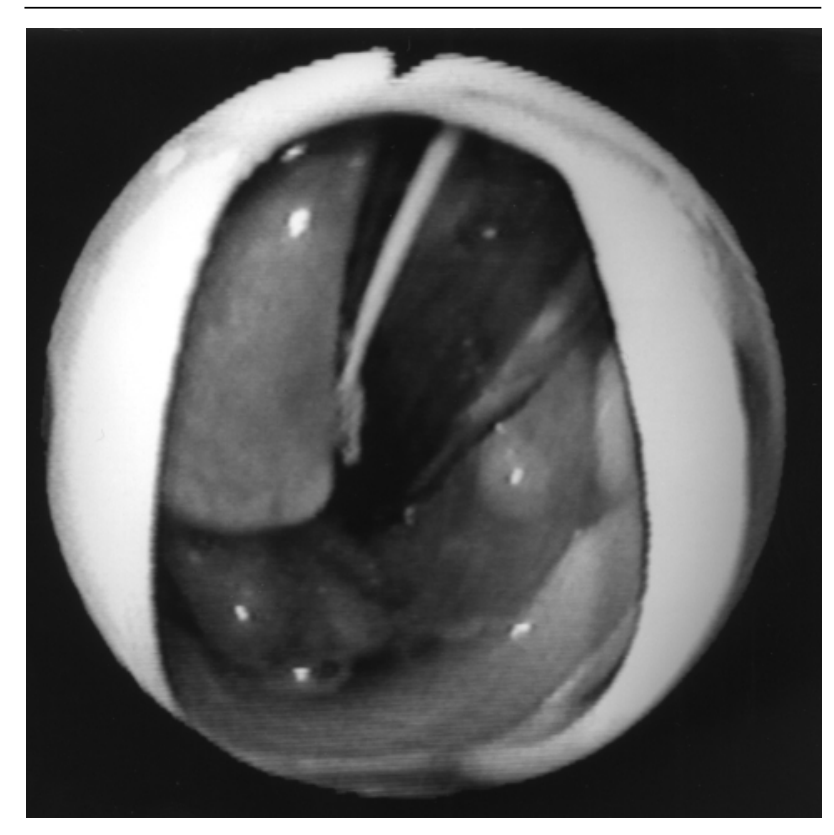

FIGURE 2 Fibreoptic visualization of the epiglottis. The laryngeal mask (LM) is fully inserted into the hypopharynx.

LM and resort to an alternative airway technique. In no case did the oxygen saturation fall below $98 \%$ during an exchange. The fibreoptic endoscope was used in four patients to observe vocal cord function after removal of the ETT. Anesthetic emergence and LM extubation were uneventful and considered highly satisfactory in all 50 cases. There were no complications with any patient. 


\section{Discussion}

Increasingly, anesthesiologists are focussing their attention on complications associated with emergence from anesthesia and endotracheal extubation..$^{2-14,19-21} \mathrm{~A}$ recent study suggested, in fact, a greater incidence of respiratory complications associated with endotracheal extubation than with endotracheal intubation. ${ }^{21}$ Common problems occurring with endotracheal extubation include coughing and bucking, laryngospasm, airway obstruction, and oxygen desaturation, each of which can have a negative impact on the patient and surgical outcome.

To avoid coughing / bucking and the hemodynamic stress that occurs with endotracheal extubation, the anesthetic plan often calls for extubation under deep anesthesia. This practice may result in airway obstruction and the need for airway support manoeuvres. $^{2-13,19-21}$ Exchange of an ETT for a LM is an elegant and safe manoeuver for endotracheal extubation in these conditions. Soft tissue airway obstruction is thus avoided and the patient is then permitted a smooth emergence from anesthesia with a $\mathrm{LM}^{7}$

The most common technique of ETT / LM exchange involves first placing the LM behind the ETT, a procedure often termed "The Bailey Manoeuver" after Dr. P.M. Bailey. Dr. Bailey has recommended: ${ }^{6}$ "following surgery, leave the ETT in place, with cuff inflated. Suck out the hypopharynx. Insert the LMA and inflate its cuff. Remove the ETT with the patient still deeply anesthetized to avoid dangerous laryngeal spasm. Switch the anesthetic circuit onto the LMA and allow the patient to awaken.”

Despite published descriptions of this technique $\mathrm{e}^{6-13}$ we were, nevertheless, reluctant to perform airway exchange in the absence of prior experience and without the benefit of direct instruction. A graduated method for learning ETT / LM airway exchange was therefore utilized. We first analyzed LM positioning with a fibreoptic endoscope in 60 patients (intubated orally) without proceeding to endotracheal extubation under deep anesthesia.

Structured learning prior to performing a new airway procedure increases confidence and success, as demonstrated by Ovassapian et al. with fibreoptic nasotracheal intubation. ${ }^{23}$ Considerable practice with the LM is needed, as well, to acquire expertise as shown by Brimacombe who examined LM positioning with a fibreoptic endoscope in 1500 consecutive patients. ${ }^{16}$ Brimacombe commented that learning is likely in those "practitioners interested in developing their skills" 16 Given these expert opinions, a stepwise method for learning ETT / LM exchange seemed justified.

LM malpositioning has been reviewed extensively. ${ }^{1,17,18,23-25}$ The most dangerous LM malposition is that of "insufficient insertion depth." In this situation the tip of the LM can impinge on the arytenoids or aryepiglottic folds, resulting in glottic spasm and/or mechanical obstruction. The LM tip may enter the glottic opening, causing partial or complete airway obstruction. Passive regurgitation via the pyriform fossae is also more likely when the LM is not fully inserted. In the "learning phase" $3 / 60$ patients had "insufficient insertion depth" on the first attempt; with more than one insertion attempt, the LM could be positioned satisfactorily in all 60 patients.

Figure 2 illustrates another common finding, fibreoptic visualization of the epiglottis. The incidence of fibreoptic visualization of the epiglottis can be high $^{1,17,18}$ and occurs even when the LM is inserted to a satisfactory depth. Many authors debate, in fact, whether this is a malposition. ${ }^{17,18}$ Even when the epiglottis blocks fibreoptic visualization of the glottis (as seen from the airway tube), a satisfactory clinical airway is usually established. ${ }^{18}$ As such, our findings of a $13 \%$ incidence of fibreoptic epiglottic visualization (with the LM fully inserted) was not a cause for undue concern for undertaking ETT / LM exchange.

With the confidence and knowledge gained in our 60 patient "learning phase" study we proceeded to ETT / LM exchange in our clinical practice. From our initial study we developed two important guidelines. First, we were especially vigilant in insuring satisfactory LM insertion depth before performing ETT / LM exchange. Second, following tracheal extubation and in the event of immediate airway obstruction, we planned to deepen the anesthetic rather than remove the LM.

The Table documents our first 50 ETT / LM exchanges, and illustrates the range of cases where this procedure was found highly valuable. The LM was inserted successfully, on first attempt, in all 50 cases. Endotracheal extubation, emergence from deep anesthesia and LM extubation occurred without incident in all 50 cases. The quality of emergence was considered highly satisfactory in each case.

In summary, ETT / LM exchange is a valuable airway manoeuver that can provide a safe, smooth, emergence from anesthesia in high-risk patients undergoing complex surgeries. We describe a stepwise method to learn this well-known ${ }^{6-13}$ technique.

\section{References}

1 Brimacombe JR, Brain AIJ, Berry AM. The Laryngeal Mask Airway: A Review and Practical Guide.

Philadelphia: W.B. Saunders Company Ltd, 1997.

2 George SL, Blogg CE. Role of the LMA in tracheal extubation? (Letter). Br J Anaesth 1994; 72: 610.

3 Nair I, Bailey PM. Use of the laryngeal mask for air- 
way maintenance following tracheal extubation (Letter). Anaesthesia 1995; 50: 174-5.

4 Costa E. Silva L, Brimacombe JR. Tracheal tube/laryngeal mask exchange for emergence (Letter). Anesthesiology 1996; 85: 218.

5 Glaisyer HR, Parry M, Lee J, Bailey PM. The laryngeal mask airway as an adjunct to extubation on the intensive care unit (Letter). Anaesthesia 1996; 51: 1187-8.

6 Bailey PM. ENT Anesthesia and the LMA. In: Brain AIJ, Braun U, Bailey PM, Verghese C, Brimacombe J (Eds). The Laryngeal Mask Airway. Presented at the $11^{\text {th }}$ World Congress of Anesthesiologists, Sydney: Australia, 1996

7 Dob DP, Shannon CN, Bailey PM. Efficacy and safety of the laryngeal mask airway vs. Guedel airway following tracheal extubation. Can J Anesth 1999; 46: 179-81.

8 Asai T. Use of the laryngeal mask after tracheal extubation (Letter). Can J Anesth 1999; 46: 997.

9 Dob DP, Bailey PM. Use of the laryngeal mask after tracheal extubation (Reply). Can J Anesth 1999; 46: 998.

10 Asai $T$. Use of the laryngeal mask during emergence from anaesthesia (Letter). Eur J Anaesth 1998; 15: 379-80.

11 Koga K, Asai T, Vaughn RS, Latto IP. Respiratory complications associated with tracheal Extubation. Timing of tracheal extubation and use of the laryngeal mask during emergence from anaesthesia. Anaesthesia 1998; 53: 540-4.

12 Asai T, Shingu K. Use of the laryngeal mask during emergence from anesthesia in a patient with an unstable neck (Letter). Anesth Analg 1999; 88: 469-70.

13 Asai T, Shingu K. Capnography for safe use of the laryngeal mask during emergence from anesthesia (Letter). Anesth Analg 1999; 89: 1589.

14 Kim ES, Bishop MJ. Cough during emergence from isoflurane anesthesia. Anesth Analg 1998; 87: 1170-4 15 Brain AIJ, Denman WT, Goudsouzian NG. LMAClassic $^{\mathrm{TM}}$ and LMA-Flexible ${ }^{\mathrm{TM}}$ Instruction Manual. San Diego: The Laryngeal Mask Company Ltd, 1999.

16 Brimacombe J. Analysis of 1500 Laryngeal mask uses by one anaesthetist in adults undergoing routine anaesthesia. Anaesthesia 1996; 51: 76-80.

17 Asai T: Difficulty in insertion of the laryngeal mask. In: Latto IP, Vaughn RS (Eds.). Dfficulties in Tracheal Intubation, 2nd ed., Philadelphia: W.B. Saunders Company Ltd, 1997: 197-214.

18 Ovassapian A, Mesnick PS: The laryngeal mask airway. In: Ovassapian A. (Ed.). Fiberoptic Endoscopy and the Difficult Airway, 2nd ed., Philadelphia: LippincottRaven Publishers, 1996; 231-46.

19 Hartley M, Vaughn RS. Problems associated with tracheal extubation. Br J Anaesth 1993; 71: 561-8.
20 Miller KA, Harkin CP, Bailey PL. Postoperative tracheal extubation. Anesth Analg 1995; 80: 149-72.

21 Asai T, Koga K, Vaughn RS. Respiratory complications associated with tracheal intubation and extubation. Br J Anaesth 1998; 80: 767-75.

22 Ovassapian A, Dykes MHM, Golmon ME: A training programme for fibreoptic nasotracheal intubation. Use of model and live patients. Anaesthesia 1983; 38: 795-8.

23 Brain AIJ, Brimacombe JR, Berry AM, Verghese C. Reflux during positive pressure ventilation via the laryngeal mask airway? (Letter). Br J Anaesth 1995; 74: 489.

24 Brain AIJ. Studies on the laryngeal mask: first, learn the art (Letter). Anaesthesia 1991; 46: 417-8.

25 Brain AIJ. Laryngeal mask misplacement - causes, consequences and solutions (Letter). Anaesthesia 1992; 47: 531-2 